\title{
School Principals’ Perceptions of Students Walking and Bicycling to School
}

\author{
Liliana Rojas-Guyler, Julie Sparks, Keith A. King \\ University of Cincinnati
}

\begin{abstract}
Background. The purpose was to identify presence of restrictive policies, frequency of active commuting to school, beliefs of childhood health and perceived enabling and restrictive factors with regard to students walking/bicycling to school as observed by elementary and middle school principals. Methods. The study used a non-experimental quantitative survey research method. The census consisted of all public and private, elementary and middle schools in three counties in a Midwestern region ( $n=96$ ). Results. A total of 71 principals completed the survey (74\% response rate). Analyses indicated that the actual number of students walking/bicycling to school did not significantly differ between schools with a restrictive policy and schools with no restrictive policy. Overall, the actual number of students walking/bicycling to school was largely underestimated by principals. In addition, principals at schools with higher walking/bicycling rates were significantly more likely to report that students should consider walking/bicycling if residing within one mile, had significantly more enabling environments, and had significantly less restrictive environments.
\end{abstract}

(C) 2007 Californian Journal of Health Promotion. All rights reserved.

Keywords: School Principals, Students, Physical Activity, Elementary and Middle Schools

\section{Introduction}

The purpose of this pilot study was to identify the presence of restrictive policies toward walking/bicycling to school, frequency of commuting to school, beliefs of childhood health and perceived enabling and restrictive factors with regard to students walking and bicycling to school as observed by elementary and middle school principals in a representative group of urban and rural counties in a Midwestern region. Research abounds on the benefits of physical activity for school age children, however little has been published on the perceptions principals have about students walking or biking to school, perceived barriers and enabling factors or the existence or restrictive policies toward actively commuting to schools (walking or biking to school). The focus of this study was to conduct a preliminary analysis of perceptions principals have of issues impacting children's walking and bicycling to school behaviors. Specifically, the study focused on the beliefs, attitudes and knowledge of elementary and middle school principals in regard to their students walking and bicycling to school. Frequency of students walking and bicycling to school, opinions principals had of the environment when students traveled to school by foot or bike and if school principals were supportive of students walking and bicycling to school were also assessed.

\section{Background}

With regard to youth, studies indicate that physical activity has multiple physical and psychological benefits including controlled weight, prevented or delayed development of high blood pressure, improved psychological well-being, self-esteem and moral and social development. Specific to psychological wellbeing, physical activity is shown to reduce symptoms of depression and anxiety and enhances self-esteem, particularly in disadvantaged groups such as those with learning difficulties or characterized with low self-esteem (Cavill, Biddle \& Sallis, 2001; Centers for Disease Control and Prevention [CDC], 2000).

Several leading authorities have suggested physical activity guidelines for youth; advising 
that all children need 30 to 60 minutes of physical activity on most days of the week; including short periods of moderate to vigorous intensity (Council on Physical Education for Children of the National Association for Sport and Physical Education [COPEC/NASPE], 2004; Sallis \& Patrick, 1994; U.S. Department of Health \& Human Services [USDHHS], 1996). In Healthy People 2010, physical activity is ranked as a leading health indicator. Two main foci of the Healthy People 2010 prevention objectives include: 1) increase amount of moderate or vigorous physical activity performed by people in all population subgroups and 2) increase opportunities for physical activity through the development or enhancement of places and facilities where people can be physically active (USDHHS, 2000). According to the Youth Risk Behavioral Surveillance Survey (2006) conducted among high school students in grades nine through twelve, 9.6 percent of students nationwide had not participated in vigorous physical activity for 20 minutes or more during the last seven days preceding the survey. Additionally, according to this national data, only $35.8 \%$ of students had been physically active for a total of at least 60 minutes per day on more than five of the seven days preceding the survey. Male students reported more physical activity than females, while white students were more active than black and Hispanic students (CDC, 2006).

The independent, nonfederal Task Force on Community Preventive Services conducted a systematic review using the logic model to identify effective interventions to increase physical activity. Results indicate that the Task Force recommends or strongly recommends six interventions including community wide campaigns, point-of-decision prompts to encourage stair use, school-based physical education, social support interventions in community settings, individually adapted health behavior change, and an environmental and policy approach including the creation of or enhanced access to places for physical activity combined with informational outreach activities (Kahn et al., 2002). Key findings in regard to environmental and policy approaches suggest access to places for physical activity can be created or enhanced by the development of trails, facilities or by reducing barriers to such places. These results indicate that by reducing barriers in the neighborhood environment, selfreported exercise and energy expenditure increase, while physical activity increases to three or more days per week (CDC, 2001; Kahn et al., 2002).

Increasing evidence tends to show that land-use and transportation decisions can positively or negatively impact the physical health status and physical activity level of the community. The design and layout of cities, neighborhoods, buildings and homes all can affect community residents' involvement in physical activity (Dannenberg et al., 2003). High density neighborhoods with connected street networks and a mix of land use, where land uses are not separated by residential, commercial and industrial districts, reduces trip distance and thus are conducive to pedestrian traffic (Frank \& Engeleke, 2000; Handy, Boarnet, Ewing \& Killingworth, 2002). Conversely, increasing car use is perceived as a significant contributor in the reduction of a child's daily physical activity (Cooper, Page, Foster, \& Qahwaji, 2003). However, research indicates that walking and bicycling to school contributes to a child's daily physical activity requirements (CDC, 2002; Cooper et al., 2003; USDHHS, 1996; U.S. Department of Transportation [USDOT], 1994).

The Centers for Disease Control and Prevention (2002) analyzed data from the national HealthStyles Survey, an annual mail survey of health-related attitudes and behaviors in the United States, to examine why the majority of children do not walk or bike to school. Reported barriers to walking and biking to school include long distances (55\%), traffic danger (40\%), adverse weather conditions (24\%), crime danger (18\%), opposing school policy (7\%), and various other reasons (26\%). Accordingly, 40\% of children do not walk or bike to school due to traffic danger. Sixteen percent of respondents report no barriers to their children walking or biking to school. Children with no barriers are six times more likely to walk or bike to school as compared to the rest of the reporting group with one or more barriers. Further, studies 
indicate that parents' perceptions of barriers to child pedestrians contribute to the reduced number of youth commuting to school by foot or bicycle (CDC, 2005; CDC, 2002; Rivera, Bergman and Drake, 1989; Timperio, Crawford, Telford, \& Salmon, 2004). A review of the literature found no study which had examined principals' perceptions regarding children walking and bicycling to school. Since principals have a large impact on the policies and daily activities established at the school level, such information is important in identifying current attitudes and potential future needs.

\section{Methods}

\section{Participants}

The participants for this study were principals of public and private, elementary and middle schools in three geographically contiguous counties in a Midwestern region of the U.S. All public and private, elementary and middle schools in the selected counties were invited to participate in this pilot study. A total of 96 potential school principals were identified using the state schools directory, including 30 private and 66 public schools.

\section{Instrumentation}

The survey consisted of 36 items and had a Microsoft Word Flesch-Kincaid readability score of 8.4. Authors designed the survey questions to assess demographics, presence and awareness of restrictive policies, frequency of active commuting, various beliefs of children and health and perceived enabling and restrictive factors with regard to students walking and bicycling to school. In addition to these questions, principals were asked to obtain an actual count of how many students had walked or biked to school that day. Respondent could return the actual count of students who walked or bicycled via telephone or email (69\% reported the actual count).

Face validity of the survey was established by developing the survey based on a comprehensive review of the current literature, while a panel of researchers and principals reviewed the survey and determined content validity. To establish stability and reliability, the telephone survey was conducted with nine principals from a separate county and then repeated one week later. The results yielded a mean correlation of .922 with a range of .710 to 1.00 . Scale reliability was measured using the Cronbach alpha coefficient of reliability for the three scales in the survey. Results of these analyses showed that the enabling scale had an alpha value of .750, the barrier factors scale had an alpha value of .638 and the benefits scale had an alpha value of .516 .

\section{Procedures}

The researcher presented the concept of the study and asked for principal participation at the February 2, 2005 meeting of regional superintendents. Respective superintendents agreed to forward an email introducing the study to the principals and encouraging their participation. Telephone surveys were conducted in 2005 following Institutional Review Board approval in April of that year. The telephone survey administration lasted eight minutes on average and reached $74 \%(n=71)$ of eligible schools. In addition to the phone surveys and in order to compare rates of active commuting, the proportion of students walking and biking to school was needed in addition to the count of student, thus school populations had to be obtained. This data was gathered by two methods: 1) For public schools, the State Department of Education website "school report cards" was utilized; and 2) For private schools phone calls to each school were used to obtain the population for that school year. Once the data was gathered, the Statistical Package for Social Sciences (v14.0) software was used for all analyses with the $\mathrm{p}$ value set at .05 to determine statistical significance.

\section{Limitations}

This study was limited by participants' selfreporting accuracy, honesty of responses and potential of some participants to offer sociallydesirable answers. In addition, the study entailed a pilot study of principals in elementary and middle schools in a specific geographical area. Therefore, results may not generalize to principals and schools in different levels at different geographical regions. 


\section{Results}

The participating school principals accurately represented the geographical region and distribution of schools within the counties selected. Survey respondents indicated that 14 $(20.0 \%)$ schools were of rural location, $35(50 \%)$ schools were of suburban location and 21 $(30.0 \%)$ were of urban location. Survey participants responded that the school buildings ranged in date from 1855 to 1998 . The mean building age was 51 years. The demographic data describing survey participants indicated that $69(97.2 \%)$ of the survey participants were principals and $2(2.8 \%)$ were assistant principals. Of these participants, $37(52.1 \%)$ were female and $34(47.9 \%)$ were male. All respondents indicated graduate education with the majority $(53.5 \%)$ of survey participants holding a Rank One level of principal certification. Other survey participants responded with a master degree education level $(45.1 \%)$ or doctorate degree education level $(1.4 \%)$. The age of participants ranged from 28 to 68 and had a mean of 50.60 years $(\mathrm{SD}=8.115)$.

When asked whether their school has assessed trends with regard to how many students walk and bicycle to school, 8 (11.4\%) survey participants had indicated a response of "yes" and $62(88.6 \%)$ had indicated their school had not assessed such trends. Eight (11.3\%) survey participants indicated their school had a restrictive policy for walking or bicycling to school and $62(88.6 \%)$ survey participants responded "no." Of those reporting lack of such policy $10(14.1 \%)$ believed their school should have such policy.

Respondents were asked to provide the researcher with the approximate percentage of children walking or bicycling to school. Participants were also asked to rate their confidence level on the approximate percentage just given to the researcher. Seventy five percent of participants approximated that $17 \%$ or less of their student population walked or bicycled to school. The most frequently approximate percentage was zero $(n=71)$. The mean approximated percentage of children walking or bicycling to school was $15.19(\mathrm{SD}=25.993)$. All participants responded with a confidence level as either "very confident" (72.1\%) or "somewhat confident" $(27.9 \%)$. Participants were also asked to run an actual count of students who had walked or biked to school on the day the survey was administered. This actual count number was compared to the school's population of record for the 2004/2005 school year to achieve an actual percentage of students walking and bicycling to school on a given day. The most frequent percentage was zero $(n=27,42.2 \%)$ as seen in Table 1. The mean actual percentage of children walking or bicycling to school was 11.77 with a standard deviation of 20.854. Upon comparison of the means, a difference of $3.42 \%$ indicates an underestimation by principals of the percentage of students walking and bicycling to school.

Table 1

Frequency and Valid Percentages of Actual Percentage of Students Walking and Bicycling to School $(\mathrm{n}=71)$

\begin{tabular}{|l|c|c|}
\hline Actual Percentage & N & Percent \\
\hline 0 & 27 & 42.2 \\
\hline 1 & 10 & 15.6 \\
\hline $2-25$ & 13 & 23.6 \\
\hline $26-50$ & 7 & 11.1 \\
\hline $51-75$ & 3 & 4.8 \\
\hline $76-100$ & 2 & 3.2 \\
\hline Total & & 100.0 \\
\hline
\end{tabular}

Note. There was missing data for seven participants.

Note. Percentages refer to only valid percents. 
The actual percentage of students walking and bicycling to school was then grouped into three categories. Twenty-seven $(42.2 \%)$ of the participating schools had zero students walking or biking to school, $25(39.1 \%)$ of the participating schools had 1-25 percent of students walking and bicycling to school and 12 $(18.8 \%)$ of participating schools had 26 or greater percent of students walking and bicycling to school. The percentage of students walking or biking to school did not differ based on the existence of a restrictive school policy $\left(\chi^{2}=2.571, \mathrm{df}=2, \mathrm{p}=.276\right)$. It should be noted that the number of schools reporting a restrictive school policy may have been too low $(n=8)$ to identify significant differences.
An approximate percentage of students living within a one-mile radius of the school was asked of each survey participant, followed by a question to rate their confidence with the approximated percentage of students living within a one-mile radius of the school. Results indicated that $67.6 \%$ of the surveyed participants believed that at least half of their student population lived within a one-mile radius of the school. The mean approximated percentage of students living within a one-mile radium of the school was $41.75 \%$. Table 2 indicates approximated percentage of students living within a one-mile radius of the school as reported by survey participants.

Table 2

Frequency and Valid Percentage of Approximated Percentage of Students Living within a One-Mile Radius of the School $(n=71)$

\begin{tabular}{|l|c|c|}
\hline Approximated Percentage & $\mathbf{n}$ & $\mathbf{\%}$ \\
\hline 0 & 1 & 1 \\
\hline $1-25$ & 29 & 45.4 \\
\hline $26-50$ & 12 & 18.8 \\
\hline $51-75$ & 9 & 14.1 \\
\hline $76-100$ & 13 & 20.3 \\
\hline Total & & 100.0 \\
\hline
\end{tabular}

Note. There was missing data for seven participants

Note. Percentages refer to only valid percents.

An ANOVA test was used to find if the actual percentage of students walking and bicycling to school would differ among principals with beliefs conducive to children and health. The results show that the actual percent of students walking or biking to school was found to have a statistically significant difference for only one item (Table 3) which displays the results of the analysis of variance test. Specifically, item 7, which asked respondents to describe their level of agreement to "Students at my school should consider walking and bicycling to school if they live within a mile of school," differed. Those reporting higher percent of students walking and biking to school had higher scores on this item. That is, participants with schools with higher actual walking or biking to school rates were more likely to state that they either strongly agreed or somewhat agreed that students should walk or bike to school if they lived within one mile of the school. 
Table 3

Differences of Percentage of Students Walking and Bicycling to School Based on Beliefs of Children's Health

\begin{tabular}{|l|c|c|c|c|c|}
\hline \multicolumn{1}{|c|}{ Belief } & $\mathbf{0 \%}$ & $\mathbf{1 - 2 5 \%}$ & $\mathbf{2 6 \%}+$ & & \\
\cline { 2 - 6 } & $\mathbf{M}(\mathbf{S D})$ & $\mathbf{M}(\mathbf{S D})$ & $\mathbf{M}(\mathbf{S D})$ & $\mathbf{F}$ & $\mathbf{p}$ \\
\hline Childhood obesity is a major concern & $4.74(.447)$ & $4.58(.584)$ & $4.58(.515)$ & .720 & .491 \\
\hline $\begin{array}{c}\text { Children should be physically active at least 30 } \\
\text { to 60 minutes everyday }\end{array}$ & $4.93(.267)$ & $4.79(.415)$ & $4.83(.389)$ & .953 & .391 \\
\hline $\begin{array}{c}\text { Daily physical activity opportunities should be } \\
\text { offered during school hours }\end{array}$ & $4.37(.742)$ & $4.33(.637)$ & $4.33(.888)$ & .020 & .981 \\
\hline $\begin{array}{c}\text { Walking or bicycling to school would } \\
\text { contribute to a child's daily physical } \\
\text { activity needs }\end{array}$ & $4.04(1.126)$ & $4.46(.588)$ & $4.67(.492)$ & 2.796 & .069 \\
\hline $\begin{array}{c}\text { School offered adequate opportunities for } \\
\text { students to be physically active }\end{array}$ & $4.26(.813)$ & $4.13(.900)$ & $4.50(.522)$ & .871 & .424 \\
\hline $\begin{array}{c}\text { Students should participate in at least30 } \\
\text { minutes of physical activity during school } \\
\text { hours }\end{array}$ & $3.52(1.341)$ & $3.38(1.345)$ & $2.83(1.337)$ & 1.102 & .339 \\
\hline $\begin{array}{c}\text { Students should consider walking and } \\
\text { bicycling to school if they live within a } \\
\text { mile of school }\end{array}$ & $1.37(.884)$ & $3.29(1.459)$ & $4.42(.900)$ & 35.107 & .000 \\
\hline
\end{tabular}

Note: For statistical purposes, the actual percentage of students walking and bicycling to school was grouped into three categories: $1=0 \%, 2=1-25 \%$ and $3=26-100 \%$.

Four items measured enabling factors to walking or biking to school. These items comprised the Walking or Biking to School Enabling Scale. Cronbach alpha for these 4 items was .607. The score for the items was reverse coded to ensure that a high scale score would reflect a more enabling environment for walking or biking to school. The scale score was obtained by summing across the four scale items to obtain a scale score and ranged from 4 to $19(\mathrm{M}=12.93$, $\mathrm{SD}=3.972$ ). A one-way ANOVA test was performed to determine if the actual percentage of students walking and bicycling to school would differ based on principals' perceived enabling factors in regard to students walking or bicycling to school. It was predicted that the actual percentage of students walking and bicycling to school would be higher for principals with higher enabling scale scores toward students walking or bicycling to school. Table 4 displays the results for the analysis of variance test which show that schools with higher percentages of students walking or biking to school had higher enabling scores, or more enabling environments for walking or biking to school. 
Table 4

Differences of Percentage of Students Walking and Bicycling to School Based on Enabling Scale Score

\begin{tabular}{|l|l|l|l|l|c|}
\hline & \multicolumn{3}{|l|}{ Percent Walking Biking to School Categories } & & \\
\hline \multicolumn{1}{|c|}{ Statistic } & \multicolumn{1}{|c|}{$\mathbf{0}$} & \multicolumn{1}{|c|}{$\mathbf{2 6}$} & \multicolumn{1}{c|}{$\mathbf{2 6}$} & $\mathbf{F}$ & p \\
\hline Mean & 8.19 & 11.42 & $15.67^{\text {c }}$ & 26.518 & .000 \\
\hline Std. Dev. & 1.360 & 3.966 & 3.447 & & \\
\hline N & 27 & 24 & 12 & & \\
\hline
\end{tabular}

Note: For statistical purposes, the actual percentage of students walking and bicycling to school was grouped into three categories: $1=0 \%, 2=1-25 \%$, and $3=26-100 \%$.

Post Hoc Tukey analyses revealed that all three groups were statistically different from each other.

Six items measured restrictive factors to walking or biking to school. These items made up the Walking or Biking to School Restrictive Scale. The Cronbach alpha coefficient for the six items that make up this scale was .703 . The score for the items was reverse recoded to ensure that a high scale score would be representative of a more restrictive environment for walking or biking to school. The scale score was obtained by summing across the four scale items to obtain a scale score. The scale scores ranged from 7 to $28(\mathrm{M}=18.19, \mathrm{SD}=4.962)$.

A one-way ANOVA test was performed to determine if the actual percentage of students walking and bicycling to school would differ based on principals' perceived restrictive factors in regard to students walking or bicycling to school. It was predicted that the actual percentage of students walking and bicycling to school would be lower for principals with higher restrictive factor scale scores in regard to students walking or bicycling to school. Table 5 displays the results for the analysis of variance test. It was concluded that differences existed between the actual percentage of students walking and bicycling to school based on principals' perceived restrictive factors in regard to students walking or bicycling to school. Specifically, schools with higher percentages of students walking or biking to school had lower restrictive scores, or less restrictive environments for walking or biking to school.

\section{DISCUSSION}

There has been continued interest in the assessment and the promotion of children's physical activity due to the evidence of increased obesity and concurrent decrease in physical activity among children nationwide (Tudor-Locke, Ainsworth \& Popkin, 2001). According to Promoting Better Health for Young People Through Physical Activity and Sports, physical inactivity has contributed to the $100 \%$ increase in the prevalence of childhood obesity in the United States since 1980 (CDC, 2000). Several leading authorities suggested physical activity guidelines for youth; advising that all children needed 30 to 60 minutes of physical activity on most days of the week; including short periods of moderate to vigorous intensity (Council on Physical Education for Children of the National Association for Sport and Physical Education [COPEC/NASPE], 2004; Sallis \& Patrick, 1994; USDHHS, 1996). Studies have concluded that children who walk or bicycle to school are more physically active each day than children who do not walk or bicycle (Britt et al., 2007; Cooper et al., 2003; Cooper et al., 2005).

A variety of barriers exist for children navigating to school by foot or bike. One such barrier is a restrictive school policy in regard to children walking or bicycling to school. This study found that $11.3 \%(\mathrm{~N}=8)$ of surveyed schools had a restrictive policy in regard to walking and bicycling to school. According to data from the CDC a nationwide 2004 Consumer Styles survey $(\mathrm{N}=1588)$ showed that $6.0 \%$ of 
parents reported restrictive school policy as a barrier for their child to travel to school by walking or bicycling (CDC, 2005). On average, the number of students walking and bicycling to school has declined in recent decades. This study found that an average of $11.77 \%$ of students walked or bicycled to school on the given day of the survey. Comparatively, recent national studies indicate approximately $20 \%$ or fewer students walk or bicycle to school; a sharp decline from 1969 , when nearly $50 \%$ of students traveled to school by foot or bike and $87 \%$ of students living within one mile walked and biked to school (CDC, 2002; CDC, 2005; Young et al., 2007).

Furthermore, upon examination of the median distance to school from a child's residence, research indicated that the average median distance was two miles for children aged five to fifteen. Additionally, for those who lived less than a mile from school, walking accounted for only $31 \%$ of trips, while biking only contributed $2 \%$ of total trips (CDC, 2002; USDOT \& BTS, n.d.). Comparatively, although students who lived within one mile were not separately identified within this study, the results of this study indicated that principals $(\mathrm{N}=64)$ approximated with confident conviction (89.4\%"confident" or "very confident") that $41.75 \%$ of students lived within a mile of the school.

Several studies have asserted that principals can have a pronounced influence on the health status of students and the implementation of health programs and initiatives (Gross, Cohen \& Kahen, 2006; Rohrbach, Graham \& Hansen, 1993; Young et al., 2007).

Among beliefs of children and health, the researcher found a higher percentage of students walking and biking to school when the surveyed principals believed that children who lived within a one-mile radius should consider walking or bicycling to school. Comparatively, in a recent study of parents' perceptions of their child's pedestrian skills, Timperio et al. (2004), it was found that parents believed their 5 to 6 year old children could walk an average $1.5 \mathrm{~km}$ (.93 miles), while 10 to 12 year old children were believed to have the ability to commute 1.6 km (.99 miles). Furthermore, recent research literature surveyed parents' perceptions of enabling and restrictive environmental factors in regard to children walking and bicycling to school. Among the most cited environmental factors were distance, traffic, speed, crosswalks and weather (CDC, 2002; CDC, 2005; Timperio, 2004; Timperio, 2006). Comparatively, the present study found that greater than $50 \%$ of the surveyed population "agreed" or "strongly agreed" that sidewalks $(58.6 \%)$, crosswalks $(61.4 \%)$ and traffic $(81.4 \%)$ were among the greatest environmental factors.

In regard to pedestrian skills, the researcher of this study found that the majority of school principals believed students had adequate pedestrian skills $(54.2 \%)$ and had adequate pedestrian skills to cross low traffic streets alone (62.9\%). Comparatively, in a landmark study by Rivera et al. (1989), when parents' attitudes and practices concerning pedestrian behavior in K-4 children were examined a large proportion of parents $(93.7 \%)$ perceived five- to six-year-old children as not being able to reliably cross streets alone and $68 \%$ of parents believed that 10 -year-old children were capable of doing so.

Implications and Recommendations Recommendations for practice. The notion for students to begin walking and bicycling to school on a routine basis has garnered support across the country. National initiatives (Boarnet et al. 2005; Stuanton, Hubsmith and Kallins, 2003; Tudor-Locke et al., 2001) have shown that concentrated efforts and funds to encourage students to walk or bicycling to school have been successful in increasing the number of students commuting by foot or bike and decreasing the number of motorized vehicles within the school zone. This study contributes to a better understanding of the schools' perception of students walking and bicycling to school in addition to the enabling and restrictive factors that may convince or dissuade students and students' parents from choosing to travel to school by foot or bike. In an effort to better understand how to encourage and comfort students, parents, and school personnel in supporting children to walk and bicycle to 
school we must better understand the enabling and restrictive factors in local neighborhood environments. Additionally, community health educators can partner with schools to develop and implement pedestrian safety curriculum. Both classroom learning, as well as, applied practice with pedestrian skill scenarios is beneficial. Invite parents to assist with the curriculum or organize a parents meeting to review the curriculum and teach correct pedestrian skills to parents.

Overall, few students reported walking or biking to school. Most principals reported being supportive and particularly so of students who live in close proximity. Most principals reported environments that were not enabling for walking or biking. However, crime did not seem to be a factor for the large majority of principals. Principals were split on reported restrictive barriers to walking or biking to school. The actual percent of students walking or biking to school was higher for schools with more enabling environments and lower for schools with more restrictive environments. Based on these findings we need to continue to work with principals to increase physical activity and walking or biking to school seems like an option they are open to exploring further. Work needs to be done to further improve the presence of enabling factors and decrease the presence of restrictive barriers to walking and biking to schools. Principles can play an integral role in this process and should be part of the team along with community and school health educators as we continue to target physical activity and health improvement among school children.

\section{Research \\ Recommendations for Future}

Recommendations for future research include a full scale study beyond piloting the instruments and methods with a small number of counties. Studies examining school personnel specifically, understanding principals', teachers' and superintendents' roles in student pedestrian behavior. Furthermore, few studies have identified the implications of restrictive school policy in regard to actively commuting to school. Future complementary studies could examine those schools with no restrictive policies; understanding why principals are not interested in restrictive policies; examining the steps involved in making new policy or the perceived importance of such policies and determining if policies differ based on geographic location.

As larger schools with increasing student populations are constructed, students are commuting farther distances. Few studies have identified student pedestrian programs that address distance as a barrier to walking or bicycling to school. Other such restrictive barriers, including specific crime related behavior, such a sexual offenders, could also be examined in future studies. Finally, research that identifies and develops validity for pedestrian survey tools, which individuals could use to survey their local community, would be beneficial. These tools could assist communities in identifying local issues and developing action plans.

\section{References}

Cavill, N., Biddle, S., \& Sallis, J. F. (2001). Health enhancing physical activity for young people: Statement of the United Kingdom expert consensus conference. Pediatric Exercise Science, 13, $12-25$.

Centers for Disease Control and Prevention. (2001). Increasing physical activity: A report on recommendations of the task force on community preventive services. Morbidity and Mortality Weekly Report, 50(RR-18); 1-14.

Centers for Disease Control and Prevention. (2002). Barriers to children walking and biking to school United States, 1999. Morbidity and Mortality Weekly Report, 51(32); 701-704.

Centers for Disease Control and Prevention. (2005). Barriers to children walking and biking to schoolUnited States, 2004. Morbidity and Mortality Weekly Report, 54, 949-952.

Centers for Disease Control and Prevention. (2006). Youth risk behavior surveillance - United States, 2005. Morbidity and Mortality Weekly Report, 55(SS05), 1-108. 
Centers for Disease Control and Prevention. (2000). Promoting better health for young people through physical activity and sports: A report to the president from the Secretary of Health and Human Services and the Secretary of Education. Retrieved December 28, 2004, from http://www.cdc.gov/nccdphp.dash/presphysactrpt

Cooper, A. R., Page, A. S., Foster, L. J., \& Qahwaji, D. (2003). Commuting to school: Are children who walk more physically active? American Journal of Preventive Medicine, 25, 273-276.

Council on Physical Education for Children (COPEC) of the National Association for Sport and Physical Education. (2004). Physical activity for children: A statement of guidelines for children ages 5-12 (2nd ed.). (Issue Brief No. 0-88314-910-9). Reston, VA: Author.

Dannenberg, A., Jackson, R. J., Frumkin, H., Schieber, R. A., Pratt, M., Kochtitzky, C., \& Tilson, H. (2003). The impact of community design and land-use choices on public health: A scientific research agenda. American Journal of Public Health, 93, 1500-1508.

Ewing, R., Schmid, T., Killingsworth, R., Zlot, A., \& Raudenbush, S. (2003). Relationship between urban sprawl and physical activity, obesity, and morbidity. American Journal of Health Promotion, 18(1), 47-57.

Frank, L., \& Engeleke, P. (2000, December). How land use and transportation systems impact public health: A literature review of the relationship between physical activity and built form (ACES: Active Community Environments Initiative Working Paper \#1).

Gross, S., Cohen, H.A. \& Kahan, E. (2006). Survey of parents, nurses, and school principals on their perceptions of the controversial role of school in health promotion. Pediatrics International, 48(1), 44-47.

Kahn, E. B., Ramsey, L. T., Brownson, R. C., Heath, G. W., Howze, E. H., Powell, K. E. et al. (2002). The effectiveness of interventions to increase physical activity. American Journal of Preventive Medicine, 22(Suppl. 4), 73-107.

Rivara, F. P. (1990). Child pedestrian injuries in the United States: Current status of the problem, potential interventions, and future research needs. American Journal of Disabled Children, 144, 692-695.

Rivera, F. P., Bergman, A., \& Drake, C. (1989). Parental attitudes and practices toward children as pedestrians. Pediatrics, 84, 1017-1021.

Rohrbach, L. A., Graham, J. W., \& Hansen, W. B. (1993). Diffusion of a school-based substance abuse prevention program: predictors of program implementation. Preventive Medicine, 22, 237-260.

Sallis, J. F., \& Patrick, K. (1994). Physical activity guidelines for adolescents: Consensus statement. Pediatric Exercise Science, 6, 302-314.

Timperio, A., Ball, K., Salmon, J., Roberts, R., Giles-Corti, B., Simmons, D. et al. (2006). Personal, family, social, and environmental correlates of active commuting to school. American Journal of Preventive Medicine, 30(1), 45-51.

Timperio, A., Crawford, D., Telford, A., \& Salmon, J. (2004). Perceptions about the local neighborhood and walking and cycling among children. Preventive Medicine, 38, 39-47.

Tudor-Locke, C., Ainsworth, B., \& Popkin, B. (2001). Active commuting to school: An overlooked source of children's physical activity. Sports Medicine, 31, 309-313.

U. S. Department of Health and Human Services. (2000). Healthy people 2010: Understanding and Improving Health (2nd ed.). (DHHS Stock No. 017-001-001-00-550-9). Washington, DC: U. S. Government Printing Office.

U. S. Department of Transportation. (1994). National bicycling and walking study: Case Study No. 1: Reasons why bicycling and walking are and are not being used more extensively as travel modes (Publication No. FHWA-PD-92-041). Washington, DC: DOT, Federal Highway Administration.

U. S. Department of Transportation, Bureau of Transportation Statistics. (n.d.). Journey to work trends in the United States and its major metropolitan areas, 1960-1990. Retrieved February 4, 2004, from http://ntl.bts.gov?DOCS/ 473.html 
Young, D. R., Felton, G. M., Grieser, M., Elder, J. P., Johnson, C., Lee, J.S. et. al. (2007). Policies and opportunities for physical activity in middle school environments. The Journal of School Health, 77(1), 41-47.

$\underline{\text { Author Information }}$

Liliana Rojas-Guyler, PhD, CHES*

Assistant Professor

University of Cincinnati

Department of Health Promotion and Education Program

PO Box 210068

Cincinnati, $\mathrm{OH} 45221-0068$

Ph.:513 5560993

Julie Sparks, Director

Wellness Mercy

Cincinnati, $\mathrm{OH}$

Keith A King, PhD, CHES

Associate Professor

University of Cincinnati

Department of Health Promotion and Education Program

PO Box 210068

Cincinnati, OH 45221-0068

* corresponding author 